\title{
La participación del odontólogo en el control del cáncer oral: Manejo en la prevención, tratamiento y rehabilitación. Revisión
}

\author{
Participation of dentist in oral cancer control: management in \\ prevention, treatment and rehabilitation. Review
}

Casariego ZJ*

\section{RESUMEN}

El cáncer es una enfermedad compleja siendo una de las mayores causas de morbilidad. La mortalidad es alta, ya que menos del $50 \%$ de los pacientes curan. El odontólogo tiene una única oportunidad de reconocer neoplasias malignas cuando ellas todavía son asintomáticas e insospechadas. Por lo cual, la detección temprana de una lesión, combinada con una tratamiento adecuado, parecería ser el modo más efectivo para mejorar el control del cáncer. De ahí la importancia del odontólogo, quien adquiere una real responsabilidad en el manejo del cáncer oral, desde el diagnóstico hasta la rehabilitación.

En la mayoría de los casos, éste es el primer clínico consultado ante un dolor bucal y tiene la responsabilidad de diferenciar entre una lesión precancerosa y una malignidad y la derivación oportuna.

Confirmado el diagnóstico por los expertos, los programas de salud pública son críticos hoy en día en enfatizar la necesidad del examen odontológico de rutina previo y promover un estado de salud bucal.

El tratamiento del cáncer oral a menudo produce disfunciones y distorsiones en el habla, masticación, salivación, dolor de las piezas dentales y de la mucosa, de ahí que la rehabilitación oral es la mejor consideración que se le puede brindar al paciente. El control óptimo del cáncer oral necesita de una cantidad de medidas entre muchos profesionales de la salud.

La complejidad de un diagnóstico óptimo, manejo y control requiere de un equipo multidisciplinario..

Palabras clave: Neoplasias malignidad, insospechadas, control óptimo.

\section{SUMMARY}

Cancer is a complex disease, beeing a major cause of morbidity. Mortality is high, with less than $50 \%$ of oral cancer patients have no cure. Dentist have a unique opportunity to detect malignant neoplasms while they are asymptomatic and unsuspected. Hence early diagnosis of a lesion, combined with adequated treatment, seems to be the most effective way to improve oral cancer control. Therefore the importance of dentist who share a relevant responsibility in the management of oral cancer, from diagnosis through rehabilitation.

The dentist is most often the first clinician consulted for oral complaints and therefore has the responsibility of differentiating bening from precancerous and malignity and the opportunity to early derivation.

* Ex Profesora Titular de Patología y Clínica Estomatológica (4/2007).

Profesora Titular de Farmacología y Terapéutica Aplicadas.

Facultad de Odontología de la Universidad Nacional de La Plata.

Directora del la Carrera de Posgrado de Especialización en Estomatología Clínica en UCA.

Aprobada por Coneau).

zulemacasariego@hotmail.com. 
When diagnosis is comfirmed by experts, the public health programs are critical in emphasizing the need for a previous routine oral examination, in order to promove oral health before oncologic therapy

Treatment of oral cancer oftem produces certain dysfunctions in speech, mastication, swallowing and dental and mucosa complains, therefore, oral rehabilitation becomes a major consideration to the patient.

Optimal oral cancer control calls for a diversity of approaches among many health professionals.

The complexities of optimal diagnosis, management and control require a multidisciplinary team..

Key words: Neoplasms, malignity, unsuspected, optimal control.

Fecha de recepción: 2 de septiembre 2008.

Aceptado para publicación: 10 de septiembre 2008.

Casariego ZJ. La participación del odontólogo en el control del cáncer oral: Manejo en la prevención, tratamiento y rehabilitación. Revisión. Av. Odontoestomatol 2009; 25 (5): 265-285.

\section{INTRODUCCIÓN}

"Si el cáncer oral es detectado tempranamente, existe una posibilidad del 80 al 90\% de sobrevida. La detección temprana del cáncer oral depende de un examen completo por un dentista u otros representantes de la salud bucal calificados."

Bristish Dental Journal 2006; 200,246.

En algunas oportunidades, le toca al odontólogo tener la primera sospecha y luego la confirmación, del diagnóstico de un carcinoma de la cavidad bucal, ya sea en la mucosa, en el órgano lingual o en los anexos.

No todos los odontólogos tendrán la oportunidad o la elección de formar parte de un equipo de atención al paciente oncológico.

Sin embargo, éste debe llegar a ser una lectura informativa y formativa dentro de la comunidad odontológica, en una sociedad, en donde las cifras estadísticas sobre cáncer bucal van en aumento.

El diagnóstico clínico debe realizarse ante la presencia de aquellas lesiones que la Organización Mundial de la Salud en el año 2005 considera como precursoras de cáncer, "las manchas blancas (leucoplasia), manchas rojas (eritroplasias) y manchas blancas y rojas (leucoplasias moteadas y eri- troleucoplasia) y carcinoma in situ “. (1) Anteriormente se había agregado, la úlcera traumática.

En un matutino acreditado de Buenos Aires, se ha publicado en el mes de agosto del 2006 con grandes caracteres, que el cáncer bucal presenta estadísticas cada vez mayores en la juventud debido especialmente al uso indiscriminado del cigarrillo y del alcohol.

Para recordar, los estados clínicos asociados con un incremento significativo de riesgo para desarrollar una lesión precursora de cáncer según la OMS, son: "deficiencia de hierro, liquen plano oral, fibrosis oral submucosa, sífilis, xeroderma pigmentoso, epidermólisis ampollar y lupus eritematoso sistémico" $(1,2)$.

Los carcinomas a células escamosas corresponden al $90 \%$ de los tumores malignos de la cavidad oral y del orofaringe.

Básicamente, ante una tumoración en los tejidos bucales o anexos o en la región cervical, el profesional debe establecer un diagnóstico diferencial, en lo posible semiológico, de tres etiologías posibles: congénita, infecciosa y neoplásica. Pero este diagnóstico clínico presuntivo debe iniciarse con una anamnesis completa del enfermo, interrogando sobre sus antecedentes familiares de enfermedad y/o deceso, incidiendo en sus antecedentes clínicos, en sus hábitos tóxicos (especialmente tabaco y alcohol), trau- 
matismos o irradiación previa, antecedentes de otros tumores, la ingesta de comida no controlada y no balanceada, su hábitat anterior y actual, su trabajo o profesión.

Una consideración importante en este aspecto es la edad del paciente. Clásicamente se han establecido tres grupos de edades: pediátrica (menores de 13 años), adultos jóvenes (de 16 a 40 años) y adultos (mayores de 40 años) (3).

Esta simple clasificación no solamente puede ubicarnos en la estadística de los tumores malignos y edad, si no que, puede facilitar el diagnóstico. En el caso de adenopatías presentes, en relación con la edad, por ejemplo, las tumoraciones cervicales en la edad infantil o en el adulto joven localizadas en la línea media o debajo del músculo esternocleidomastoideo, son de crecimiento rápido, de características agudas y corresponden a masas hísticas inflamatorias y cervicales congénitas.

Por el contrario, la presencia de adenopatías en cuello aumentadas de tamaño en el paciente adulto o mayor, localizadas en el trayecto de cadenas ganglionares unilaterales, mayores de $2 \mathrm{~cm}$, dolorosas a la palpación, de consistencia dura y no desplazables en los planos profundos, de crecimiento rápido y progresivo en los tres o cuatro meses, en un paciente con antecedentes de fumador y hábito de tomar bebida alcohólica en forma crónica, estará indicando una metástasis nodular maligna (12\% de los tumores de cabeza y cuello) o, un linfoma (5\% de todos los tumores y $55 \%$ en la edad infantil).

En este último caso, las lesiones no poseen características inflamatorias y en ocasiones se acompañan de fiebre, sudoración nocturna, pérdida de peso y prurito. Estas patologías se presentan en una forma o con un cronograma bimodal, con un pico que va de los 15 a los 30 años y otro alrededor de los 50 años, con predominio del sexo masculino (4).

Un elemento a tener en cuenta también es el perfil somático genético. Aquel paciente en el que sospechamos la existencia de una lesión maligna. Se pueden realizar hoy en día estudios, gracias a la biología molecular y estudios de especificidad y confiabilidad (PCR).
Los carcinomas a células escamosas de la cavidad bucal y de la zona oro faríngea contienen variaciones génicas, especialmente de algunos protooncogenes, influenciadas por la acción de varios agentes causales y, ello lleva a las diferentes presentaciones clínicas. Por ejemplo, los carcinógenos provenientes del tabaco aumentan las mutaciones y el nivel del protooncogén p53 y desproporcionalmente involucran a las mujeres y la neoplasia maligna aflora en lengua, en comparación con el grupo control de pacientes no fumadores (5). O sea, que el estudio de los mecanismos que regulan la proliferación celular de las neoplasias, permite cada vez más avanzar en su conocimiento, existiendo una verdadera batería de marcadores biológicos, además del p53, (el más estudiado). O sea: la observación sobre la pérdida de cromosomas específicos se ha asociado a la reversión celular hacia la malignidad, sugiriendo este hecho solamente que, un único cromosoma (y quizá un solo gen) puede ser suficiente para suprimir la tumorogénesis o lo contrario. Por último, actualmente se considera a la radiación como inhibidora del factor de crecimiento epidermal (EGFR) y existen numerosos artículos publicados sobre la capacidad de este factor de influenciar en el crecimiento, proliferación y diferenciación celular, habiendo sido asociado a tumores de alta agresividad (5-9).

El práctico general no está asociado a estos estudios generalmente. Pero no puede desconocerse su existencia, sobre todo porque la terapia antitumoral está relacionada en la actualidad y desde ya hace unos años, con la utilización de los descubrimientos de la biología molecular de los tumores.

Diagnosticada la lesión cancerígena por el odontólogo consultado, o bien derivado el paciente por el equipo oncológico para solucionar algún problema dental, el tratamiento a seguir por los oncólogos especializados será la cirugía, la quimioterapia, la radioterapia o estas dos conjuntamente.

\section{¿CUÁL DEBE SER LA ACTITUD DEL ODONTÓLOGO EN ESTE MOMENTO?}

La radioterapia está considerada como un arma importante para el tratamiento de los tumores, sola o en combinación con la cirugía y la quimioterapia. 
En la actualidad existe una tendencia creciente hacia la implementación de tratamientos menos tóxicos que pueden ser administrados en forma prolongada luego de la extirpación del tumor (10).

La cirugía extirpa la masa tumoral, la quimioterapia y la radioterapia destruyen los restos del tumor en crecimiento y el tratamiento prolongado mediante antihormonas, factores antiangiogénicos, factores antiinvasivos, antiseñales, antitelomerasa y vacunas, los cuales modulan el comportamiento autónomo o agresivo de las células tumorales residuales. Por ejemplo se tiene en cuenta el llamado "reloj biológico". Hace más de 30 años se descubrió que, del $50 \%$ al $70 \%$ de las células van alcanzando un estado de senescencia replicativa que culmina en la muerte. El reloj biológico cuenta la división celular a través de la erosión progresiva de los extremos de los cromosomas o telómeros. En cada división los telómeros se replican en forma incompleta y las hebras del ADN se acortan progresivamente, así cuando el material genético alcanza un límite crítico, las células comienzan un viaje hacia su final.

La telomerasa es una enzima que resintetiza el ADN de la región telomérica. El $98 \%$ de las células tumorales tiene telomerasa, por consecuencia son inmortales, nunca envejecen. Las células normales en cambio, no tiene telomerasa) y este hecho el que se tiene en cuenta para cierto tipo de quimioterapia (11).

La radioterapia puede ser administrada desde el exterior como la cobaltoterapia o bien in situ, mediante agujas, con un material radioactivo que se inserta en el seno del tumor. Esto se conoce como radioterapia intersticial o braquiterapia. Ambas técnicas destruyen en forma eficaz las células tumorales, pero además son absorbidas por los tejidos orales adyacentes y en forma especial, por aquellos que poseen una elevada capacidad de renovación. La radiación de alto voltaje, si bien produce menos lesiones cutáneas, penetra más profundamente pudiendo dañar las estructuras óseas y provocar lo que se conoce como una osteorradionecrosis (12).

Por lo cual, si bien la primera etapa del odontólogo correspondió a la realización de una completa anamnesis, la segunda ha de ser:

\section{Una exhaustiva exploración de la cavidad bucal}

La planificación del tratamiento odontológico del paciente oncológico que va a ser irradiado, estará condicionado por una serie de factores, unos relativos a la característica personal del paciente y otros sobre los métodos terapéuticos a aplicar. Se considerará el estado de salud o enfermedad de las piezas dentarias, del periodonto, de la mucosa bucal, de los arcos desdentados, y de todas las zonas estomatológicas. La exploración de las glándulas salivales, conductos y los ostiones, es de relevancia.

\section{Preparación de la boca}

Si una tumoración hace eclosión en cualquier zona o, si se presenta una lesión ulcerada o exofítica, deben eliminarse todas aquellas aristas, cúspides en punta, obturaciones mal adaptadas o no pulidas, o sea, todo aquello que pueda estar lesionando aún más, el lecho de injuria neoplásico. El tártaro aplicado en las caras y cuellos dentales debe ser también eliminado.

Se ha de constatar la existencia de un plano dentario o dentario-protésico de oclusión, el cual le permita al paciente ocluir y deglutir sin dificultad. Los movimientos mandibulares y la existencia de un probable crujido de la articulación temporomandibular también deben incluirse en este examen preliminar.

Si es necesaria la exodoncia de dientes no recuperables por problemas pulpares, periodontales u oclusales, impactación, o existencia de focos sépticos apicales o paradentales, debe ser realizada antes de la radiación. Las prótesis desadaptadas deberán prepararse para el nuevo estado bucal.

Para las manipulaciones quirúrgicas se ha establecido un tiempo mínimo antes de la radiación, que es de entre 15 y 20 días. Los tejidos deben estar reparados y no debe existir ninguna solución de continuidad en la mucosa bucal o en los huesos alveolares para cuando comience el tratamiento radioterápico. 
En caso en que haya sido necesario una alveolectomía u osteotomía, o si hubo fractura de la pared alveolar o se presentó una alveolitis post extracción, el límite mencionado deberá prolongarse, naturalmente. No olvidar que tanto los fármacos antineoplásicos como las radiaciones ionizantes elevadas sobre los maxilares causan hipoxia como consecuencia del daño de las células endoteliales de los vasos. Estos se edematizan, se producen estenosis y se reduce el aporte sanguíneo al tejido óseo, dando lugar a la necrosis y a la infección.

\section{Reducir la infección al mínimo es primordial}

Existe una colonización microbiana, de bacterias y hongos dentro del microfilm que se organizan en entramados complejos o películas biológicas o biopelículas que son causa de las enfermedades con más riesgos.

Se presentan adaptados a las paredes dentales y tejidos de inserción, en forma de verdaderos barnices vivientes. Estos permiten que otros organismos oportunistas patógenos, interactúen por medio de señales locales o sistémicas durante los episodios de supresión inmune, como consecuencia de los tratamientos oncológicos.

La diversidad de ambientes químicos también puede permitir que varias especies bacterianas vivan y convivan sin problemas. Son las condiciones locales las que regulan la producción de toxinas y de otros agentes desencadenantes de enfermedades elaborados por las células microbianas que crecen en estas capas. Un ejemplo es la placa dental. Por cultivo varios autores han aislado 509 diferentes variedades, entre 51.000 bacterias detectadas en los cuellos dentarios de 300 personas, las cuales están organizadas espaciotemporalmente en 4 dimensiones en comunidades (13-16).

\section{¿CUÁLES SON LOS MÉTODOS DE ATAQUE DEL BIOFILM EN LA CAVIDAD BUCAL?}

Las células bacterianas que flotan libremente en la cavidad bucal se depositan sobre una superficie, se organizan en grupos y se fijan en ellas.

\section{¿Cuáles son sus objetivos?}

Recubrir las superficies con moléculas que impidan la sujeción del biofilm ya que, las células agrupadas comienzan a segregar una matriz de adherencia sobre las superficies duras y blandas y, por medio de gradientes químicos, favorecen la coexistencia de las colonias bacterianas entre sí, sus distintos estados metabólicos y su intercambio de señales.

\section{¿Cuáles son los métodos de ataque?}

1. Cubrir las superficies duras y blandas de la cavidad bucal con moléculas que impidan la agregación de las bacterias y la fabricación de la matriz.

2. Aplicar sustancias bloqueantes de las señales bacterianas en las zonas de riesgo.

3. Aplicar combinados de antibióticos o medicamentos locales con poder bacteriostático y preferentemente bactericida para atacar las variadas estratagemas de supervivencia utilizadas por las células del biofilm.

Costerton y Stewart (17), en sus trabajo publicado sobre películas bacterianas, refieren que resulta muy difícil para un medicamento local difundirse hacia el interior de la micro colonia si reacciona con las células de la matriz extracelular. En su metodología aplicada en 1991 para estudiar la estructura de las biopelículas, demostraron que las bacterias crecían en pequeños enclaves, que no suelen constituir ni la tercera parte de la materia presente en los mismos, ya que el resto es una sustancia blanda y pegajosa secretada por ellas y que invariablemente absorbe agua y atrapa partículas pequeñas. Esta sustancia o baba espesa a la que se le llama matriz extracelular es la que tiene unidas a las microcolonias y la que se pega a las superficies.

Las bacterias están separadas pero, a la vez, intercomunicadas por una red de canales de agua. Este líquido aporta nutrientes disueltos y elimina productos de desecho. Las células más superficiales están bien servidas mientras que las más profundas, están sometidas a un suministro bajo o escaso. Las del centro, también sobreviven. Los cambios ambientales dentro de la película varían de acuerdo a las distintas profundidades. Por microscopía confocal se 
comprobó que las concentraciones de oxígeno pueden variar radicalmente entre posiciones tan próximas como separadas por tan solo una centésima de milímetro.

La diversidad de ambientes químicos que surgen dentro de una misma biopelícula implica que, el aspecto que presente una célula y su modo de actuar puedan ser muy diferente de los de su vecina aunque, éstas sean genéticamente iguales. Esto implica el hecho que algunas células pueda que ocasionen poco daño y las otras sean extremadamente peligrosas.

Los autores sostienen entonces que la placa dental es una biopelícula y que es sorprendente que un número creciente de pruebas se relacione la placa dental con las dolencias cardíacas.

\section{¿Cómo podríamos actuar para vencer los cuatro tipos de ataques mencionados anteriormente?}

Un compuesto activo, que tiene la propiedad de adicionarse a las superficies como antimicrobiano, cuya estructura común es de dos moléculas de guanidina y por eso se la llamó biguanida, es la Clorexidina o Clorhexidina (1-1'-Hexametileno Bis 5 (p-clorofenil) Biguanida.

Se utiliza como alguna de las tres sales siguientes: diacetato; digluconato y diclorhidrato. La primera se presenta como un polvo cristalino blanco que se disuelve en 50. El digluconato, como una solución al $20 \%$ P/V en agua, incolora y amarillenta, que admite más diluciones en agua y hasta en 5 volúmenes de alcohol o hasta 3 de acetona. El diclorhidrato como un polvo blanco soluble en agua (1 en 400), en alcohol ( 1 en 450$)$ y en propenlinglicol ( 1 en 50 ).

Hoy en día se presenta en el mercado el Digluconato de clorhexidina, solución al $12 \%$, (sin alcohol y con xilitol $10 \%$ ) lo cual es más placentero para su uso. La Clorhexidina es uno de los antisépticos de mayor sustantividad pero su nivel antiséptico es más activo in vitro que in vivo. De todas maneras tiene actividad contra bacterias gram + y gram- y menos acción contra pseudomonas y proteus. Las bacterias pre- sentes en una gingivitis hiperplásica, hipertrófica, hemorrágica o necrotizante aguda, demandan la efectividad de este medicamento. Es inactivado por la sangre y otras materias. Tiene bajo poder de sensibilización y toxicidad. A menudo se le agregan surfactantes catiónicos o no iónicos para mejorar sus propiedades detergentes y humectantes. El efecto producido es bacteriostático en $\mathrm{pH}$ neutro, bactericida en ph 5,6 a media concentración y bactericida en ph ácido 3,5 en concentraciones altas (18).

Actualmente existe en el mercado farmacéutico la forma de gel la cual facilita la aplicación por parte del paciente

Puede ser usado como reemplazante del dentífrico y, si el cepillo dental es bien utilizado, la llegada a todos los ángulos y caras o superficies de la pieza dentaria puede ser muy efectiva. En caso de sensibilidad o molestia, la aplicación digital en forma de masaje gingival puede también ser aconsejable

Se puede adoptar esta forma de aplicación (con el dedo, o con una torunda de algodón o gas o esponja, siendo más sencillo el aplicador que viene adjunto con la jeringa para el gel), en el caso que el propio paciente esté inhabilitado para realizarlo.

Se aconseja su uso cada 4 horas por los datos positivos generados en estudios clínicos aleatorizados.

El uso de aciclovir oral está indicado en pacientes que tienen serología positiva para el herpes simple. La profilaxis a la reactivación de este virus ha mejorado en forma espectacular la morbilidad asociada a la mucositis por irradiación.

El tratamiento antifúngico también está recomendado antes o durante el tratamiento radioterápico bajo el uso de comprimidos de < nistatina y/o clotrimazol.

Si el estado bucal es realmente séptico, se puede de todas maneras indicar los antibióticos más indicados para estos casos.

En aquellos pacientes con estado buco dental aceptable a bueno y que son colaboradores, es necesario adoptar una serie de medidas preventivas, tales como el control de la placa bacteriana y aplicación de fluo- 
ruros con ph neutro, para evitar la aparición de nuevas caries.

Antes de la irradiación se podrán obtener impresiones de las arcadas dentarias con el fin de construir cubetas individuales dentro de las que se colocará flúor o bien, se podrán confeccionar cubetas intraorales protectoras plomadas, útiles cuando se utiliza la radioterapia intersticial.

Los límites inferiores de estas cubetas preferentemente deberán prolongarse

Hacia los tejidos de inserción (surcos) con resina blanda para protegerlos y, también a los maxilares. Deben tener un espesor de $5 \mathrm{mn}$ en la zona próxima, frente a la irradiación y llevan en su interior un papel plomado. También pueden confeccionarse en siliconas.

Se han indicado las condiciones dentales empleadas para establecer los factores de riesgo (FRD) para el paciente oncológico que va a ser irradiado introdujeron el nuevo concepto de factores de riesgo relacionados con el cáncer (FRRC) el cual se define como "cualquier factor de riesgo no dental relacionado con el cáncer, con su terapia y con las condiciones médicas del paciente que aumentan el riesgo de complicaciones orales tras el tratamiento radioterápico y/o quimioterápico".

El concepto fundamental del operador, en este caso el Odontólogo, ha de ser conocer las prioridades que un enfermo de cáncer tiene y tratar de cubrirlas (19).

Silvestre-Donat y colaboradores (20) justifican la presentación de dilemas clínicos en el pre-tratamiento dental de los pacientes con cáncer. Sostienen que el cuidado óptimo del paciente, también depende de un análisis minucioso del equilibrio entre beneficios e inconvenientes de las atenciones clínicas. Utilizan un método de categorías en escala, diferenciando entre dientes estratégicos y no estratégicos, para signar valores a los resultados del tratamiento dental. En la tabla que confeccionaron se encuentran registrados los hallazgos clínicos en la enfermedad periodontal, la enfermedad pulpar y lesión periapical, caries de dientes no funcionales y la higiene oral, información dental y cooperación. Al mejor resultado le otorgaron un valor de 1 , el peor de 0 y los valores inferiores a 0,3 se consideraron negativos e indeseables.

La atención del odontólogo estará enfocada hacia la prevención y el control del estado de la cavidad bucal, permanentemente.

"La Oncología Radioterápica ha evolucionado de un modo espectacular hacia la sofisticación tecnológica y la integración multidisciplinaria en las últimas dos décadas. Esta especialidad médica requiere no sólo la provisión de tratamientos complejos técnicamente sino la participación de profesionales sanitarios particularmente implicados en el objetivo de proporcionar una atención individualizada al paciente con cáncer. Los cuidados de soporte en Oncología Radioterápica integran aspectos diagnósticos y terapéuticos con la afinidad de aliviar la morbilidad física y psicológica inherente a la enfermedad y a los tratamientos antineoplásicos".

"La amplitud de los cuidados de soporte necesarios exige crear espacios para el desarrollo de otros profesionales. El oncólogo radioterapeuta debe comprender que su papel como "actor principal" de los cuidados de soporte es insuficiente y limitado. Probablemente sea más propio, dada la diversidad de tareas que hay que acometer, adoptar el rol de director de escena y permitir la incorporación de nuevos actores que, en momentos puntuales, pueden asumir el papel de "actor principal" (21).

Existen circunstancias, sobre todo en territorios tan extensos como el nuestro en el cual contamos con características y deficiencias dispares en cuanto a la salud pública se refiere.

La escasez de los recursos técnicos sumamente costosos para nuestro medio, la carencia de enfermería especializada, y los servicios hospitalarios cada vez más saturados por la demanda asistencial y de tratamientos, hace que generalmente, la atención individualizada de soporte de los pacientes no llegue realizarse.

No podemos prever a cuál odontólogo le va a tocar el rol de "actor principal" en un equipo médico-oncológico de tal magnitud, fortuitamente o deliberadamente. 
Por lo cual, en nuestra realidad, podemos afirmar que es sumamente necesario que todo odontólogo deba estar preparado para asumir tal rol.

En primer lugar, se le indicará al paciente que deberá omitir el uso del tabaco, el alcohol y comidas con irritantes. Ingerir comidas blandas y húmedas, licuar los alimentos, lubricarlos con cremas o aceites, evitar también los alimentos ásperos, los excesivamente calientes o fríos, aquellos que se adhieren al paladar o se pegan a los dientes e ingerir pequeñas porciones de comida y masticarlas muy bien.

La aparición del dolor puede manifestarse como efecto del propio tumor por pérdida de la barrera epitelial, ulceración y exposición de nervios, infección secundaria, o bien como respuesta emocional, debida al temor a la neoplasia y a los tratamientos. Una correcta evaluación del dolor permitirá valorar el comienzo, la duración, la variación en su intensidad y la ubicación

La etiología del dolor en los pacientes oncológicos en un $70 \%$ es provocada por: La afectación del tumor en forma directa: por la invasión al tejido óseo, por la invasión o la compresión, por la obstrucción o invasión vascular o por la ulceración de la mucosa.

Menos del $10 \%$ padecen de lo que se conoce como síndromes paraneoplásicos representados por espasmos, neuralgias, debilidad y otros.

El dolor provocado por los procedimientos de diagnóstico o terapéuticos se calculan en un $20 \%$ y son aquellos resultantes de biopsias, aspiración, postquirúrgicos, post irradiación, etc.

Mientras que el dolor no relacionado con la neoplasia maligna se considera en un $10 \%$.

Existe una escala de valoración llamada simple que considera los grados de dolor: ninguno, leve, moderado, fuerte, muy fuerte y el peor dolor posible. La escala numérica: utiliza una cuantificación del 0 al 10 en la que 0 es ausencia de dolor, 5 moderado, 10 el peor dolor posible. En la escala analógica visual el paciente debe ubicar un dolor según su identidad a lo largo de una línea que comienza con la ausencia del dolor y finaliza con el peor dolor posible.
El odontólogo deberá realizar mínimamente el diagnóstico diferencial entre un dolor si es de origen dental o si proviene de una obstrucción glandular por un sialolito o por el trauma de una prótesis removible o por cualquier otra lesión ajena al cáncer o, si proviene de la neoplasia en sí.

Si el dolor pertenece al primer grupo, se utilizarán las técnicas y los medicamentos usuales para pacientes no oncológicos. Por supuesto deberá considerarse a aquellos pacientes que a la vez sufren de problemas hepáticos, y/o renales, y/o son diabéticos, neutropénicos, leucémicos, hipertensos o con obstrucciones respiratorias.

Por lo cual, los regímenes terapéuticos se adaptarán a cada una de esta situaciones, independientemente del cáncer.

Para el dolor producido por su tumor, la OMS ha diseñado y propuesto una llamada, escalera analgésica, la cual consta de tres peldaños equivalentes a tres categorías de analgésicos (analgésicos menores, o no opioides, analgésicos opioides débiles y opioides potentes Generalmente estos son prescritos por el clínico (aunque el odontólogo lo estudia en su currículum).

- Durante el tiempo de irradiación debe evitarse cualquier tipo de intervención quirúrgica dental o periodontal.

Durante este tiempo pueden aparecer erosiones y disminución del flujo salival. En este caso se prescribirán sialagogos (pilocarpina, comprimidos de $5 \mathrm{mg}$, dos a tres veces al día), o goma de mascar con xilitol. Se pueden usar salivas artificiales las cuales contienen polímeros protectores del tipo de carboximetilcelulosa o, enzimas salivales como lactoperoxidasa y lisozima.

Científicos en el laboratorio Dr. David Wong en la Escuela Dental de UCLA han descubierto últimamente en la saliva, siete marcadores biológicos en el RNA, que permiten detectar el cáncer bucal. Estos están presentes en niveles muchos más altos en pacientes con cáncer oral que sin cáncer. Éste es el primer test estandarizado de saliva para la detección del cáncer clínico oral y tendrá un enorme va- 
lor en cuanto llegue al mercado mundial, reduciendo la mortalidad y morbilidad. (No existe aún publicación).

Últimamente se ha optimizado la terapia por radiación., y han aparecido nuevas estrategias para el tratamiento del cáncer.

El creciente conocimiento sobre la progresión en ciclo celular, las respuestas a las diferentes dosis de los diferentes tumores y las bases de reparación del daño al ADN ha sido muy importante.

Ha surgido así la Radiobiología para el estudio de la acción de la radiación ionizante en tejidos vivos. "Si alguna forma de radiación es absorbida por un material biológico existe una posibilidad que interactúa directamente con la estructura DNA (acción directa) o con otras moléculas en la célula, particularmente agua, produciendo radicales libres que alcanzarán y dañarán puntos clave. La radiación a dosis clínicas induce un vasto daño del DNA, que generalmente es reparado por la misma célula". "La radiosensibilidad cambia a través del ciclo celular, siendo la fase G2 tardía y la Mitosis las más sensibles y la fase $\mathrm{S}$ (cuando el DNA se replica) y la temprana de G2 las más resistentes".

Bajo estos conceptos la aplicación de las dosis están destinados a tomar a la célula en su ciclo más sensible y auxiliado por la presencia de oxígeno se produce peróxido libre que ayudaría a matar a la célula neoplásica. La combinación de estos dos agentes hace que se necesiten menos dosis para lograr los mismos efectos.

En este contexto se habla de radio protección. O sea, protección de los tejidos sanos que se realiza con este fraccionamiento de "tumores y tejidos que responden temprano y tumores y tejidos que responden tarde. SE busca así disminuir la dosis para disminuir el daño que se realiza a los tejidos normales y, con el auxilio de ciertos radio protectores químicos como Amifostina.

Nuevos conceptos también indican inhibir la función $\mathrm{y}$ actividad de algunos protooncogenes como $p$ 53, ras y el factor de receptores del crecimiento epidermal (EGFR) para inhibir la toxicidad.
Un tema bastante critico es la fibrosis post radiación la cual parece ser en parte revertida, por el uso de la Pentoxifilina y el Tocoferol.

Aunque gracias a la detención temprana muchos cánceres se presentan como tumores localizados, una buena parte de los pacientes suelen presentar metástasis, años después de la intervención quirúrgica. La detención de células malignas en la circulación o de sitios ocultos, sería de suma utilidad para definir el pronóstico de un paciente y planear mejor el tratamiento.

Para ello se desarrollan distintos métodos de detección de células cancerosas con anticuerpos específicos basados en revelados citoquímicos o inmunofluorescencia. La reacción en cadena de la polimerasa, sistema conocido como RT-PCR amplifica en forma geométrica, una secuencia derivada del ARNm-el ácido nucleico portador de mensajes genéticos para la síntesis de proteína, característico de la variante tumoral en estudio Con ello es posible detectar la presencia de una célula cancerosa entre un millón de células normales flotando en varios milímetros de sangre. La detección en saliva amplía enormemente el panorama.

La histopatología de los tejidos involucrados muestran una verdadera necrosis de los estratos basales del epitelio y la inmunohistoquímica marca la liberación por parte del infiltrado inflamatorio, de Interleuquina 1 (IL-1) y Factor de Necrosis Tumoral alfa (TNFa), elementos pro inflamatorios del sistema inmune (22).

\section{Manejo clínico odontológico después de la irradiación}

Éste es el período en el cual van a aparecer la mayoría de las complicaciones.

Entre los tejidos más afectados podemos considerar la piel del entorno peribucal, semimucosa de labios, mucosa labial, bucal, lingual, orofaringe, glándulas salivales, piezas dentarias, con probabilidad también de los huesos maxilares.

Existe una crono patología propia de cada una de estas zonas que dependerá de la capacidad de reparación del tejido afectado. 
Los efectos tóxicos pueden ser agudos como la radiodermitis, la mucositis, y la xerostomía o, más graves como las bridas cicatriciales y/o fibrosis y, más tardíos como caries, trismus, u osteorradionecrosis.

La radiodermitis, en nuestro campo la podremos detectar a nivel de la zona peribucal y labios.

Pocos días después de comenzar la radioterapia se puede observar en algunos pacientes, un eritema que desaparecerá rápidamente pero que vuelve a presentarse a las dos o tres semanas. Este deja una piel pigmentada, oscura, que se descama fácilmente y que proviene de la atrofia de las glándulas sudoríparas y sebáceas, acompañada con áreas de alopecia. Una piel seca alrededor de los labios y mentón, no lubricados, puede ser la causa de zonas de grietas y surcos más o menos pronunciados, desagradables sobre todo para las mujeres.

Un proceso similar ocurre en la mucosa oral, al que se le denomina mucositis.

Es una inflamación reactiva que aparece como primer signo clínico al final de la primera semana del tratamiento, cuando han habido dosis superiores a 200 cGY por semana, y al cual se debe estar preparado.

Los métodos preventivos de la mucosistis mejoran la calidad de vida de los pacientes tratados con quimioterapia

Según Silverman, como en el estrato basal se ha producido destrucción de las mitosis, las células basales nuevas que las reemplacen necesitan dos semanas para su maduración, que es cuando aparecen los síntomas de la mucositis. Existe una congestión vascular en el corion el cual se traduce en vasodilatación y edema localizado con atrofia del epitelio. Esto se manifiesta clínicamente en eritema.

La pérdida de la barrera epitelial exacerba los daños producidos por agentes físicos, químicos y microbiológicos. La mucosa de la cavidad bucal, que tiene un ciclo metabólico alto, cambia precozmente durante la radiación fraccionada (200 cGy al día durante 5 por semana) se observa un eritema en la primera o segunda semana del tratamiento. Tras 2 o 3 semanas se desarrollan unas placas blancas que se conocen como mucosistis seudomembranosa en parches que luego producen en el epitelio erosiones y a veces hasta úlceras, las cuales se cubren de un exudado fibrinoso. Desde el punto de vista clínico, se agregan a este cuadro los síntomas de quemazón y dolor que el paciente refiere y que se exacerban con los alimentos.

Con cinco fracciones de 170 y 180 cGy, cinco veces por semana, el eritema es generaliza en la primera semana, y en la segunda se desarrollan las ulceraciones y pequeñas placas blancas que no son más que son acúmulos de células epiteliales, muertas, fibrina y leucocitos polimorfonucleares. En este período es común el dolor de garganta. Durante la tercera semana las placas mucosas con pseudomembranas pueden confluir y el paciente presenta síntomas muy dolorosos, con disfagia ya declarada, la cual le impide la alimentación.

La intensidad de la mucosistis está relacionada con la dosis diaria de la radioterapia, la dosis total acumulada, el volumen del tejido irradiado y el uso concurrente de agentes radiosensibilizantes o quimioterápicos inductores de mucositis.

La mucosistis aparece primero en forma más intensa en el paladar blando, los tumores amigdalinos, la mucosa bucal, los bordes laterales de la lengua adyacente o en ambas localizaciones como consecuencia de la dispersión de electrones de baja energía.

A veces la mucositis es tan intensa, que se hace necesaria la interrupción de las radiaciones En respuesta a este problema se han propuesto varios antídotos. Se ha desarrollado un estudio clínico prospectivo para estudiar el criotratamiento oral. 95 pacientes en estudio, que recibían su primer ciclo de quimioterapia con $5 \mathrm{FU}$ por vía intravenosa (tiene vida corta de 5 a 20 minutos), se distribuyeron aleatoriamente para recibir el criotratamiento oral o para grupo control. Se les indicó que se colocaran un cubo de hielo en la boca 5 minutos antes de cada tratamiento con 5FU y que lo movieran continuamente, volviendo a llenarse la boca con hielo hasta un total de 30 minutos. La mejoría fue del $50 \%$ en cuanto a la estomatitis Un estudio similar dio los mismos resultados (4) y un tercero que incluyó a 179 pacientes 
aumentó el tiempo de permanencia de hielo a 60 minutos con conclusiones aún más favorables. Cochrane confirmó que el criotratamiento oral ha sido el único tratamiento preventivo eficaz y demostrado científicamente.

Sin embrago este estudio no es aplicable a aquellos pacientes que reciben metrotexato o el 5FU por infusión continua por vía intravenosa.

La Camomila ha sido utilizada como para esta complicación, pero un estudio clínico a doble ciego realizado por el grupo "North Central Cancer Treatment Group" con sustancia placebo publicó resultados negativos.

Se han utilizados por distintos centros otras sustancias como antídotos para la mucositis, por ejemplo enjuague bucal con alopurinol, aciclovir, vitamina $\mathrm{E}$ pentoxifilina, factores estimulantes de colonias, factores de crecimientos de los queratinocitos, prostaglandina E2, sucralfato.

Una vez establecida la mucositis lo que se aconseja como medida terapéutica primera es enjuagatorios cada 24 horas con una solución de sal y bicarbonato de sodio, $1 / 2$ cucharadita de cada uno en un vaso con agua templada. Se los aconseja como calmantes pero no existe ningún estudio clínico de investigación que lo avalen (23).

Los datos clínicos y radiobiológicos indican que la prolongación en el tiempo de la radioterapia influye negativamente en la curación por la radiación de algunos tumores en el hombre, especialmente el carcinoma epidermoide de cabeza y cuello. En varios estudios retrospectivos y estudios clínicos aleatorizados demostraron un control local y una supervivencia mejores cuando se usan pautas fraccionadas con dosis mayores en un tiempo más breve y, resultado negativo, cuando se tiene que suspender o hacer una pausa de la radioterapia por causa de una mucositis severa.

Con respecto a los fármacos antineoplásicos utilizados en ciertos tratamientos. La OMS catalogó en el año 1979 los efectos tóxicos de los fármacos antineoplásicos en cuatro grados de severidad creciente (23), grado I, aparición solo de eritema, grado II ulceraciones sobre una mucosa eritematosa que permiten aún la ingestión de elementos sólidos, grado III, las ulceraciones existentes solo posibilitan la ingestión de alimentos líquidos, grado IV, impide deglutir cualquier alimento como consecuencia de las ulceraciones (1).

Tener en cuenta que, la mucosa no queratinizada es la más sensible y reactiva. Existen protocolos de atención para la mucositis, según aconseja el Instituto Nacional del Cáncer de los estados Unidos. Estos incluyen: la limpieza atraumática de los dientes y la mucosa bucal, la humidificación de los labios y el alivio del dolor y de la inflamación.

Para la limpieza de las piezas dentarias es importante evitar la laceración de la gingiva marginal y las papilas interdentarias. Se puede realizar mediante un cepillo muy suave o con una torunda de esponja, preferentemente. Cualquier solución de continuidad que produzcamos puede ser la vía de acceso a microorganismos oportunistas, como el Streptococcus viridans quien a la vez puede causar una bacteriemia.

Los alimentos blandos que el paciente ingiere en esta época y los licuados tiene la característica de pegarse a las mucosas que de por sí se encuentran secas. La limpieza se puede realizar con disoluciones bicarbonatadas tibias con agua estéril y con peróxido de hidrógeno (dilución de 1:1 en agua o solución salina normal)). El peróxido de hidrógeno está indicado en la remoción de costras. Sin embargo la utilización está contraindicada durante largo tiempo (uno o dos días máximos) puesto que su uso rutinario no agrega efectos positivos sobre la mucositis y puede aumentar la sensibilidad de la mucosa bucal $(24,25)$.

Los demulcentes son medicamentos que se aplican en forma tópica para proteger y lubricar las mucosas reemplazando a la saliva normal. Se extienden sobre las mucosas, las cubren y se adhieren a ella. La adhesividad es difícil de mantener especialmente para los vehículos grasos, liposolubles. Los mejores resultados se han obtenido con soluciones coloidales que si bien son acuosas y adhesivas debido al tamaño de sus partículas difunden muy lentamente y tardan en disolverse en el medio bucal (18). 
Las jaleas lubricantes solubles en agua, por ejemplo, clorhidrato de diclonina al $0,5 \%$ o $1 \%$, lidocaína viscosa al $2 \%$ o peróxido de carbamida al $10 \%$ son aconsejables para humedecer la mucosa y usar agentes viscosos para recubrir y protegerla. Entre ellos se encuentran el caolín con suspensión de pectina, la leche de magnesia, mezclas de hidróxido de aluminio y o suspensión de hidróxido de magnesio con suspensión de sucralfato combinadas con agentes anestésicos tópicos. (En realidad estudios comparativos y con grupo control han demostrado para el sucralfato una acción más antibacteriana que cito protectora).

El uso prolongado de la vaselina con el fin de humedecer la semimucosa labial provoca atrofia epitelial y aumenta el riesgo a la infección, pudiendo reemplazarla por preparados con lanolina.

Al realizar una adecuada observación de cada zona de la mucosa bucal el profesional distinguirá entre eritema, erosiones, ulceraciones y de ahí será la elección del tratamiento.

Con respecto al uso de antibióticos en este período, se realizaron numerosos estudios multicéntricos, aleatorizados y a doble ciego evaluando la eficacia de diversos antibióticos usados como pastillas a disolver en la boca de tobramicina, bacitracina, gentamicina, otros mezclando con anfotericina o clotrimazol, sin resultados estadísticamente significativos.

La opción de antibióticos está recomendada así como de corticoides como Prednisona 40 a $80 \mathrm{mg}$ diarios por más de una semana o, con menos efectos adversos el Deflazacort, entre $6 \mathrm{mg}$ y $60 \mathrm{mg}$ diarios de acuerdo a la gravedad y evolución.

\section{Un tema preponderante es la xerostomía}

El demulcente natural de la boca es la saliva. Ella proporciona la protección y la lubricación necesarias para que otras importantes funciones, como la fonación, la masticación y la deglución, puedan llevarse normalmente a cabo. En este cometido juegan un papel importante la viscosidad de la saliva y su contenido en mucina, una mucoproteína del tipo mucoide (18).
Debe pensarse primeramente en las enfermedades de las glándulas salivales y descartar que el paciente, previo a la irradiación no haya padecido de alguna de ellas, para lo cual será de ayuda el interrogatorio en la primera entrevista las más conocidas son: el síndrome de Sjögren, sarcoidosis, fibrosis quística, cirrosis biliar primaria, adenopatía inflamatoria quística por el $\mathrm{VIH}$, hepatitis $\mathrm{C}$, enfermedad por el virus linfotrópico $\mathrm{T}$ humano y psicosis.

Hábitos como el fumar, uso de alcohol e infusión abundante de té o cafeína pueden causar sequedad bucal.

Una revisión de las 200 drogas más frecuentemente prescritas, mostró efectos adversos orales como sequedad de boca (80,5\%), disgeusia en el $47,5 \%$ y estomatitis en el 33,9\%) (26).

Debido a que el paciente oncológico es un ser complejo, la primer medida es averiguar si está ingiriendo medicamentos o previamente estaba medicado con fármacos que, de por sí, provocan disminución del flujo salival.

En un cuantioso estudio de 1.202 individuos con una reducción del salida de saliva $(<0,1 \mathrm{ml} / \mathrm{min}-1)$ y con una sequedad bucal subjetiva, éstas estaban significantemente asociadas a la edad, al sexo femenino, a la ingesta de psicotrópicos, a antiasmáticos, antidiuréticos, y antihipertensivos. La sequedad subjetiva y el flujo aún reducido, se presentan fuertemente asociados a la depresión, ansiedad, y tristeza permanente.

La edad es muy importante ya que los hipnóticos son consumidos sobretodo

Por personas de edad adulta y adulta avanzada.como benzodiacepinas, opioides, analgésicos, etc.

La secreción promedio de la saliva en el hombre es de $750 \mathrm{ml}$ a 1 litro en 24 horas. Es variable a lo largo de la vida. Durante el sueño desciende notablemente, se hace intermedio durante el reposo (o $5 \mathrm{ml}$ por minuto) y asciende bastante durante las comidas ( 2 ml por minuto).

Recordar que la producción de saliva por las glándulas está regulada por una doble inervación vegetativa: 


\section{La excitación del parasimpático provoca una secreción abundante y fluida.}

2. La excitación del simpático produce una saliva espesa y con abundantes proteínas.

1. El principal neurotransmisor del parasimpático es la acetilcolina, las cual interactúa con receptores situados en los ácinos glandulares. Estos receptores recogen las señales que llegan al citoplasma de las células acinares que, activadas liberan una secreción primaria hacia la luz de los conductos o ductos en donde se carga de electrolitos y así completa llega a la cavidad bucal.

2. El principal neurotransmisor del simpático es la noradrenalina, la cual actúa igual que la anterior.

Teniendo en cuenta esta fisiología, podemos también considerar una alteración debida problemas en el estímulo eferente, en la inervación de una u otra de las vías mencionadas o a nivel del Sistema nervioso central.

Para realizar un diagnóstico de certeza sobre el flujo salival hay que medirlo por lo menos 2 horas después de la última ingesta líquida o sólida, de la higiene bucal, de haber fumado para que estos estímulos no influyan sobre su producción.

El paciente debe salivar dentro de recipientes milimetrados, maniobra que se repite cada 2 minutos. Luego el registro máximo del contenido del tubo se divide por 6, que son los minutos durante los cuales se colectó la saliva sin tragarla y se compara con las tablas de secreción.

El registro medio es de 0,3 a 0,5 ml por minuto. Normal es de 1 a $2 \mathrm{ml}$ por minuto. El límite de xerostomía sería de $0,2 \mathrm{ml}$ y si hay una patología es de o, $1 \mathrm{ml}$ por minuto.

Al terminar la prueba se le da al paciente parafina o goma para mascar y se repite la prueba (27).

Existe evidencia que un número de drogas o la exposición mínima a ellas atentan contra la estimulación espontánea de la salivación, especialmente por los agentes simpático miméticos, agentes que afectan a la serotonina, y noradrenalina como a otras drogas, bien supresoras del apetito o inhibidoras de protea- sa, las cuales pueden producir una boca seca subjetiva.

En una encuesta de 3.311 personas, de las cuales $21,3 \%$ eran hombres y $27,3 \%$, mujeres, estas últimas reportaron más boca seca que los primeros y, hubo una fuerte comorbilidad entre la prevalencia de boca seca y la farmacoterapia.

En pacientes con avanzada edad y cáncer, la xerostomía fue el cuarto síntoma común que presentaron (78\%) (26).

El mecanismo de acción más importante de las drogas que producen xerostomía se basa en el efecto anticolinérgico. En la periferia, los receptores muscarínicos, especialmente los receptores 3 (M3R) median la neurotransducción parasimpática colinérgica a las glándulas salivales (y lacrimales), existiendo otros mecanismos menores, mediados por otros receptores endógenos. Las drogas más utilizadas por los pacientes que comienzan a tener depresiones e inestabilidad emocional, debido a la patología que nos ocupa, y la obsesión de la idea del dolor y de la muerte, son los antidepresivos y las benzodiacepinas.

La psicofarmacología de la depresión es un campo que involucra una rápida evolución desde las últimas cinco décadas. La medición del efecto inhibitorio de la salivación, después de la administración de varios antidepresivos, los divide en:

a) Aquellos con mínimo efecto salival (ixocarboxaside y lithium).

b) De leve efecto (zimelidine y nomifensine).

c) Con efecto moderado (nortryptilie e imipramine entre otros).

d) Con pronunciado efecto clomipramine, amytriptiline, y otros).

Hoy en día se utilizan generalmente el Bupropion, Oxybutynin y Tolterodine con varios reportes publicados sobre uno de los efectos adversos más molestos para los pacientes como es la disminución del flujo salival. (Estos últimos antagonistas de los receptores alfa).

El primero, originalmente fue desarrollado como antidepresivo y es un inhibidor selectivo (recapturan- 
te) de la dopamina y noradrenalina. Sin embargo se descubrió que reduce los impulsos de la imperiosa necesidad o urgencia de fumar. Debido a que una de las primeras recomendaciones del paciente oncológico, especialmente de cara y cuello es el no fumar, debería tenerse en cuenta que esta droga produce disminución severa del flujo salival. Como además entre los efectos adversos se cuenta el dolor de cabeza, insomnio, agitación, temblor y náusea en más del $10 \%$ de los pacientes, se la ha cambiado muchas veces por sertralina. Las diferencias no han sido significativas (26).

Es conocido que los opioides producen disminución de flujo salival y las benzodiacepinas como el Diacepán, usados como ansiolíticos e hinópticos y muchas veces como automedicación, acentúan este efecto.

La clásica triple terapia contra el Helicobacter pylori es amoxicilina, tetraciclina, metronidazol y un derivado del bismuto. La adición de estas drogas a un antagonista del receptor $\mathrm{H} 2$ puede llevar a rangos publicados de erradicación del Helicobacter pylori pero la sequedad de la mucosa bucal ha sido encontrada en un $41 \%$ de los pacientes (Kaviani et al (26).

Los ejemplos pueden ampliarse a cantidad de fármacos que los pacientes ingieren diariamente por automedicación.

La xerostomía como consecuencia de la irradiación, aparece como una degeneración de las células acinares y ductales, cuando las glándulas salivales mayores están dentro del campo de incidencia.

La prevención de la xerostomía inducida por la radiación ha sido objeto de numerosos estudios en los últimos años.

Suele presentarse en forma progresiva a las dos semanas del tratamiento y mejora en algunos casos entre los seis y doce meses, aunque en pacientes que reciben altas dosis totales de radiación, el proceso puede resultar irreversible. La saliva comienza siendo más espesa y viscosa, con falta de humedad en la boca, debido a que primeramente se afectan las glándulas de tipo seroso, como las parótidas. Progresivamente se observa un deterioro de las fun- ciones bucales básicas como la formación del bolo alimenticio, la masticación y la deglución. La disminución del flujo salival también dificulta la sujeción de las prótesis completas mucosoportadas y favorece la aparición de caries y candidiasis.

Según Silverman (25), la exposición de las glándulas salivales mayores en el campo de ionización por irradiación induce fibrosis, degeneración grasa, atrofia acinar y celular y necrosis de las glándulas. Los ácinos serosos parecen ser más sensibles que los mucosos. La disminución del flujo salival así como su consistencia y duración varía de paciente a paciente. La recuperación de los signos indeseables lleva meses y la recuperación de un adecuado confort puede no lograrse en 6 meses o un año y, en otros, permanece indefinidamente anormal.

La producción depende de la cantidad de tejido salivar lesionado, si ha sido incluido en el campo de radiación y de la dosis suministrada. Si solamente se encuentran en el campo de radiación la glándula salival y sublingual los pacientes pueden notar escasa alteración en la producción salival, aunque ésta sea suficiente para predisponer la aparición de caries.

Las consecuencias de la sequedad son:

1. La saliva no lubrica haciéndose espesa y filamentosa.

2. Se pierde su capacidad neutralizante.

3. El ph de 4,5 en una boca limpia y seca causa desmineralización, el depósito mineral está imposibilitado y la producción de ácido después de exposición al azúcar da lugar a desmineralización de los dientes y conduce a la caries dental.

El diagnóstico de la xerostomía pos radiación puede hacerse mediante una sialometría cuantitativa que evalúe la disminución del flujo salival, tanto de la saliva total basal como de la estimulada, teniendo en cuenta los conceptos ya escritos anteriormente.

El tratamiento de la hiposalia depende de si el parénquima funciona o ha sido dañado. Esto puede evaluarse en un primer momento con la prueba de colocar un terrón de azúcar en la cavidad bucal y observar clínicamente la respuesta. 
Se puede aumentar la frecuencia de ingestas al día, siempre recomendando una extrema higiene bucal con chorro de agua, gel de flúor, gel de clorhexidina, limpieza de prótesis si la hubiera, hidratantes bucales o se puede recurrir a fármacos que estimulen la función glandular.

Los resultados obtenidos con pilocarpina han sido variables, siendo negativo el mayor de los estudios controlados con placebo efectuados. La pilocarpina es un alcaloide muy similar al neurotransmisor parasimpático, la acetilcolina, que actúa sobre los mismos receptores que ésta aunque con diferentes efectos cardiovasculares. La forma farmacéutica es de comprimidos de $5 \mathrm{mg}$, administrados dos o tres veces al día o bien, en gotitas instiladas en el suelo de la boca a una concentración del $2 \%$.

La pilocarpina aumenta el flujo salival después de 30 minutos de ser ingerida, aunque en algunos casos la respuesta se alcanza después del uso continuado. Es un sialogogo, fármaco simpático mimético, cuyos efectos principales se ejercen sobre el receptor muscarínico colinérgico de las células acinares de las glándulas salivales. Ha sido el único fármaco sialogogo aprobado por la Administración de Alimentos y Drogas de los Estados Unidos, aunque últimamente ha aprobado a la amifostina a partir de los estudios clínicos efectuados, aunque los efectos adversos limitan su uso en algunos casos. Parece que ésta droga protege a las glándulas salivales de los efectos de la radioterapia en la etapa temprana y tardía.

Los efectos adversos de la pilocarpina aumentan con la dosis. El más importante es la sudoración excesiva, también figuran náuseas, escalofríos, rinorrea, vasodilatación, mayor lagrimeo, urgencia y mayor frecuencia urinaria, astenia, dolor de cabeza, diarrea y dispepsia.

Los resultados obtenidos con el uso de pilocarpina tópica son similares a los descritos en su uso sistémico.

Otro fármaco útil es la Anetoletitriona que aumenta el número de receptores de la superficie de las glándulas acinares. Se ha hablado ya de los sustitutos salivales y medidas preventivas aconsejadas por el Instituto Nacional de Cáncer de los EEUU que dice:
"Los pacientes deberán:

- Efectuar una higiene meticulosa higiene bucal al menos 4 veces al día (después de cada comida y antes del descanso nocturno).

- Utilizar pasta dentífrica con flúor.

- Aplicar un gel de flúor sobre los dientes limpios antes de acostarse. (El flúor es ineficaz en dientes cubiertos con placa bacteriana). Este procedimiento ha demostrado su utilidad en la reducción de la incidencia de caries en pacientes irradiados. Es aconsejable aplicar el gel al 1\% mediante férulas que se mantendrán colocadas 5 minutos.

- Practicar enjuagues entre 4 y 5 veces al día con una solución confeccionada ca base de sal y bicarbonato de sodio (1/2 cucharada de sal y 1/2 de bicarbonato de sodio en una taza de agua caliente) Este procedimiento neutraliza el ambiente ácido bucal relacionado con la xerostomía y limpia y lubrica la mucosa bucal.

- Evitar alimentos con alto contenido de azúcar".

La yohinbina, un antagonista de los adrenorreceptores alfa, pareciera ser más efectivo que la anetholtrithiona. Clorhidarto de yohinbina, comprimidos $5 \mathrm{mg}$, envase con 30 y 100 comprimidos.

Recientemente, años 2003 (28-30) y 2007 (31), se han recibido varias publicaciones sobre la seguridad y la eficacia de productos en base a aceite de oliva, botaina y xilitol los cuales reducen la xerostomía provocada o inducida por polimedicación a que son sometidos algunos pacientes o, que por automedicación, sienten los efectos adversos de la ingesta diaria de varios fármacos. Recomendados como tópicos, colutorios, dentífricos y gotas bucales parecen ser una solución bastante recomendable por los estudios presentados.

Se han producido ya comercialmente, con venta en España.

La xerostomía puede mejorar si se pone en la habitación del paciente o en la cabecera de la cama un vaporizador o un humidificador

Además de la xerostomía, en cuanto al flujo salival se refiere, el mismo tejido salival puede experimen- 
tar un aumento agudo de volumen aproximadamente en el $5 \%$ de los pacientes tras doce horas después de la primera sesión de radioterapia. Se manifiesta en forma indolora y solo una sensación de tensión en la glándula. La fiebre, la demasiada tensión psíquica, el dolor y secreciones purulentas, estarán indicando infecciones de las glándulas, por lo cual se deberá instalar un tratamiento antibiótico por vía oral o endovenosa, según la gravedad del caso.

En el futuro, el uso de pautas de radioterapia de intensidad modulada (RTIM) y de modificaciones de fraccionamiento puede preservar mejor la función de las glándulas salivales.

\section{Pérdida del gusto}

La pérdida de gusto (ageusia) se produce rápidamente al iniciar el ciclo de radioterapia en la cavidad bucal. Aparece primeramente en la parte posterior y dorsal de la lengua, en donde se localizan las grandes papilas vellatas y en las papilas fungiformes que ocupan la mayor superficie, siendo ambas las más sensibles a la radiación. Los pacientes irradiados pueden peder parte (hipogeusia) del gusto o tener una confusión de gustos y disminuidos (disgeusia) de salado, dulce, amargo y agrio. También en este tema se habla de un componente variable e individual para la recomposición. Tal pérdida produce en los pacientes pérdida de apetito, desgano, pérdida de peso, hiposalivación, y la ausencia de degustar los alimentos y sentir placer por ello, causa depresión, frustración y ausencia de voluntad para cocinar. Esto se complica si hay alteraciones de salivación, y aún más, si ha sido dañada por la cirugía alguna zona de importancia dentro de los tejidos bucales. Después de terminar la radioterapia los pacientes describen alguna mejoría a las 2 o 3 semana, pero recuperan el gusto recién a los 4 meses aproximadamente. En algunos pacientes el gusto nunca vuelve a ser normal.

Los suplementos de Znc son recomendados diariamente en una dosis de $100 \mathrm{mg}$, sin embargo no existen estudios aleatorizados controlados con placebo para determinar el valor de zinc. Se aconseja también el uso de amifostina para la prevención de la pérdida del gusto.

\section{Candidiasis}

Los efectos tóxicos de la quimioterapia son usualmente agudos $y$ pueden añadir morbilidad al tratamiento.

El aumento al riesgo a las infecciones es particularmente importante no solamente para la salud de los tejidos periodontales y de las piezas dentarias sino para toda la cavidad bucal, la cual puede ser sitio de infecciones causadas por bacterias adquiridas, hongos y virus.

La reactivación de la familia del herpes virus como el Virus herpes 1 y el de la Varicela Zoster puede causar infecciones secundarias. Las infecciones bacterianas pueden producirse por patógenos oportunistas tales como: Pseudomonas, Klebsiella, Serratia, Escherichia Koli, etc.

Las infecciones por Cándida son comunes en los pacientes irradiados y en aquellos que tienen alterado el flujo salival (32).

Los signos y síntomas clínicos suelen confundirse con los de mucositis. Sin embargo es fácil y surge como consecuencia el cambio de la Candida saprófita a la patógena, al alterarse la humedad del medio bucal, el calor y el ph. La Candida patógena se distingue como tal por sus características de emitir pseudohifas, las cuales se adhieren y penetran en el epitelio, labrándose espacio entre e intra celularmente por impacto físico y químico. El primero gracias a su "raspatorium" que le permite abrirse camino y avanzaren forma mecánica y segundo, por las enzimas que segrega.

La duración del tratamiento depende del control de los signos y de su recurrencia. El tratamiento será local y sistémico.

Las tabletas de cotrimazol o de nistatina se contraindican debido a que el paciente tiene dificultad en disolverlas por la falta de saliva y por la mucositis. Por lo cual se prefieren colutorios, especialmente de clorhexidina y sin son tolerados, sirven también para controlar la flora microbiana existente sobre las piezas dentarias. Buches con Violeta de Genciana son también recomendables. La administración sistémi- 
ca diaria, con la comida, de Fluconazol $100 \mathrm{mg}$ es efectiva. Será de gran ayuda el mantener la boca húmeda.

Es muy importante vigilar una probable o posible infección con Aspergillus, el cual es mucho más mórbido y de consecuencias sistémicas a veces mortales.

\section{Examen previo y restauración protésica}

Desde el punto de vista protésico, deberá realizarse también un diagnóstico previo al tratamiento de cirugía/ quimio/radioterapia con el objeto de evaluar si el paciente es dentado, edéntulo total y/o parcial y si ya es portador de prótesis o no.

En servicios hospitalarios en donde se atienden a pacientes con pocos o ningún recurso económico, se evaluará la posibilidad de poder utilizar la prótesis que portaba el paciente antes de la consulta para su remodelación, si es posible.

El planeamiento protésico es una verdadera rehabilitación, esencial en el cuidado de este paciente, que debe ser considerado ya, desde el momento del primer diagnóstico o derivación.

Existen, por lo tanto, distintos tiempos y consideraciones a tener en cuenta:

1. Conocer la localización del tumor y en qué zona se va a realizar la exéresis de la misma.

Los pacientes que van a requerir una rehabilitación maxilofacial son arbitrariamente clasificados de acuerdo a su tratamiento postquirúrgico, defectos y morbilidad en: defectos maxilares, de la lengua, mandibular y defectos faciales.

2. Con respecto a los defectos maxilares, la mayoría de los tumores de los senos paranasales, paladar o glándulas salivales menores requieren una maxilotomía parcial o total a partir de la línea media generalmente (a veces abarcan ambos lados) y puede a la vez estar involucrado un colgajo del labio o de mejilla o de ambos.

En la zona palatal depende hasta donde llegan los bordes. Los defectos en el paladar duro y blando producen una variedad de problemas, desde un habla casi ininteligible, dificultad en la masticación, particularmente si el paciente es edéntulo, como es difícil obtener un cierre periférico y la estabilidad de la prótesis en su lugar. Los líquidos son muy difíciles de contener en la cavidad bucal y ser ingeridos, ya que fluyen lo mismo que las comidas hacia la cavidad nasal y a la nariz. Estos defectos den ser solucionados por la prótesis de rehabilitación o epitesis.

Es de costumbre que una prótesis, temporaria, que actuará como un verdadero obturador, sea instalada en el momento de la cirugía. Este es uno de los pasos que el odontólogo debe calcular y realizar previamente en conversaciones con el o los cirujanos. Los problemas protésicos que se vislumbren en la prognosis protética deben ser discutidos con el equipo quirúrgico.

Se tomarán impresiones, realizarán modelos de estudio y, de trabajo, estudio radiográfico y de relaciones intermaxilares.

Durante el período de cicatrización, esta prótesis debe ser realineada periódicamente con selladores temporarios, para compensar el cambio de las estructuras que soportan a los tejidos adyacentes al defecto. Generalmente se calcula que a partir de los 3 a 4 meses puede comenzar a realizarse la prótesis definitiva.

Un apósito quirúrgico puede ser ubicado en el defecto y, estos obturadores inmediatos harán de matriz, minimizando así la contaminación en la herida en el postoperatorio inmediato y permitiendo al paciente hablar y salivar inmediatamente después de la cirugía. Luego que ese apósito quirúrgico es retirado ( 6 a 10 días después de la cirugía) la prótesis debe ser realineada con un sellador temporario.

Los problemas principales de estos obturadores son la estabilidad, la retención y el soporte. Si existen dientes remanentes hay que evaluarlos muy bien previamente, pues serán los que soportarán la estructura protésica. Las prótesis unilaterales son las más difíciles, pues están en imbalance y los dientes del lado de retención sufren el stress de toda la dentición durante la función. De modo que en este momento temprano, estas prótesis deben considerarse como verdaderos obturadores y tienen como misión fundamental mantener la separación entre la cavidad nasal y bucal, restaurar el habla, mantener 
la salivación dentro de la boca y proveer un soporte para la mejilla y el labio.

Los defectos de los tejidos se restablecen mucho mejor con una prótesis instalada que sin ella.

Cuando la herida se cicatriza por completo ( 3 a 5 meses después), recién se comienza con la confección de la epitesis definitiva.

La mayoría de las prótesis deben ser readaptadas ya en el primer año, porque cambios pequeños pero continuos de los tejidos periféricos tienen lugar en el defecto quirúrgico.

Los problemas surgen cuando se requiere tratamiento prostético para aquellos pacientes que han sufrido pérdida del paladar blando o la pared lateral de la faringe. Este es un capítulo que merece ser estudiado ya con mucho detenimiento, sobre todo por la actividad de los músculos del velo del paladar y el nasofaringe.

3. Cuando los defectos son de la lengua y de la mandíbula dan como resultados deshabilidades en el habla, en la salivación en los distintos movimientos de desplazamiento de la mandíbula, y toda esta disfunción se traduce en un verdadero tormento social para el paciente.

La naturaleza y los grados de disfunciones secundarios a la resección de la parte anterior de las mandíbula y /o del órgano lingual suponen problemas muy serios.

La cirugía reparadora tiene su primera función y será un vestíbulo plastia, lograr una continuidad mandibular, una creación de mucosa queratinizada que mediante distintos tipos de injertos facilitará la confección de una prótesis total.

En caso de no repararse el hueso mandibular con un injerto homólogo de costilla o de cresta ilíaca, la localización de rejillas de titanio adaptadas a la forma necesaria son de gran utilidad. Actualmente el mercado de traumatología provee una variedad abundante para poder seleccionar a necesidad.

La instalación de implantes óseo integrados mejora notablemente la estabilidad de las prótesis obturatrices en pacientes desdentados como así también en aquellos que solo necesitarán prótesis parciales por poseer aún dientes remanentes.

En estos casos, los principios básicos que se aconseja tener en cuenta son: a) La mayoría de los conectores deberán ser rígidos.

b) Las piezas remanentes tendrán que soportar las fuerzas en forma perpendicular al plano de oclusión.

c) Deberán confeccionarse también planos de oclusión guías a fin de facilitar la estabilidad de las prótesis en los movimientos.

d) La retención deberá llegar hasta los límites fisiológicos de los tejidos periodontales.

e) El máximo soporte y estabilidad deberán ser logrados gracias a las superficies blandas de los tejidos remanentes, incluyendo los límites del defecto (29).

Deberá realizarse un control estricto sobre la ausencia de roces o traumatismos, o áreas de excesiva presión, especialmente en los bordes del defecto quirúrgico, en todo el recorrido o pasos del tratamiento prostodóncico. La necrosis de los tejidos y la facilitación de infecciones deben ser evitadas y la instrucción y educación del paciente en cuanto a la higiene de los tejidos y de las prótesis cobran muna importancia crucial.

La remoción y la instalación de la prótesis o epítesis deberán ser precedidas por un estacionamiento de las mismas, por algunos minutos, en una solución al $12 \%$ de clorhexidina, para eliminar la población de microbiótica existente sobre su superficie.

\section{Osteorradionecrosis}

Es una de las complicaciones más serias de los tratamientos por irradiación en los cánceres de cara y cuello.

Las células óseas son destruidas así como su vascularidad, problema la mayoría de las veces irreversible, y que va progresando a medida que se implementan más sesiones a través del tiempo y/o la agresividad de la intensidad del tratamiento. Las lagunas producidas por la reducción de osteocitos, osteoblastos y osteoclastos pueden llevar a fracturas patológicas. Debido a ello el hueso se va necrosando por zonas, apareciendo así los llamados secuestros que no son más que fragmentos desvitalizados de tejido que se van a desprenden espontáneamente 
del resto del cuerpo óseo o quedar como involucros. Esto sucede, sobre todo, cuando se produce una infección. El riesgo es mayor en pacientes desdentados. Y si posee algunos dientes, estos sufren a la vez, de modo que terminada la terapia y de acuerdo a lo aconsejado anteriormente, deberán extraerse.

Algunas veces se produce la exposición espontánea de un trozo de hueso aún pasado un año después de la irradiación.

Un estudio publicado de la Universidad de California (30) realizado sobre 100 pacientes irradiados, publicaron, entre otros conceptos, que todo los pacientes fueron observados por lo menos cada 6 meses. El tiempo en el cual se desarrolló la osteorradionecrosis fue variable y en el grupo de pacientes edéntulos, se manifestó en un rango de tiempo de 10 meses después del tratamiento. En el grupo dentado, entre 6 y 72 meses (rango 22 meses).

Por lo cual los datos estadísticos de incidencia y prevalencia varían, dependiendo de la institución que ha realizado el reporte, la agresividad de la radioterapia, y el tiempo de seguimiento.

El hecho que se produzca una radio necrosis espontánea ésta es imprescindible según Beumer (33) pero, está en relación sobre todo con las dosis utilizadas y con el tamaño del hueso. El riesgo se aumenta en paciente dentados, más aún si las piezas dentarias fueron extraídas inmediatamente después de la radioterapia. Los cambios en la piel o en la mucosa podrían estar adelantando una osteorradionecrosis.

El tratamiento es difícil y corresponde a la parte médica utilizar los medios terapéuticos entre los que parece ser de gran efectividad la cámara de oxígeno (hiperbárica), con el soporte antibiótico y quirúrgico para la remoción de secuestros e involucros.

De lo expuesto, se ve la necesidad de desarrollar un protocolo general para la prevención de complicaciones bucales aplicables a todos los centros de radioterapia de cabeza y cuello, en primera instancia.

En nuestro país en donde existen muchas ausencias y deficiencias de normas bien definidas en el tratamiento bucal de estos pacientes, puede ser benefi- ciosa la difusión de conceptos claros que sirvan de información individual y para el mundo odontológico en general.

La mayoría de los pacientes no están enterados que los estudios de la carrera universitaria de odontología comprende no solamente todos los conocimientos y prácticas destinadas a la conservación y terapéutica de las piezas dentarias, si no que también le brinda al futuro profesional una preparación médico-odontológica referente a las distintas enfermedades del cuerpo y de la cavidad bucal con sus músculos, glándulas y huesos, síndromes de desarrollo, infecciones, enfermedades alérgicas y auto inmunes, y también sobre lesiones precursoras de cáncer y carcinomas.

\section{BIBLIOGRAFÍA}

1. Barnes L, Evenson JW, Reichart P, Sidransky D. Pathology and Genetics of Head and Neck Tumours. World Health Organization Classification of Tumours. IARC Press, 2005; Lyon.

2. Gale N, Pilch BZ, Sidransky D, El Naggar A, Califano J, et al. Epithelial precursor lesions.In (Pathology and Genetics of Head and Neck Tumours. WHO, OMS). p. 177.

3. National Cancer Institute. Surveillance, Epidemiology and End Results Program (SEER) 19831993.

4. Shin DM, Lee JS, Lippman SM, et al. p53 Expression Predicting recurrence and second primary tumors in head and neck squamous cell carcinoma. J Natl Cancer Inst.1996; 88:519-29.

5. Sereno Moyano M, Espinosa Arranz E, Castelo Fernández E, González Barón. Biología Molecular de los cánceres de Cabeza y Cuello.Rev Oncol 2003;5(9):500-10.

6. Yuspa SH, Hanssen L, Luowei LL, Joseloff E, Weinberg W, Fernández Salas E. Interacting Signale Pathways in the Pathogenesis of Squamous cell Carcinoma. Simposia Cellular Mechanism of Signal Transduction.Medicina Buenos Aires 2000; 60:689-92. 
7. Christensen María. The EGF receptor system in head and neck carcinomas and normal tissues. Danish Medical Bolletin. April1998; 45 (2):12113411-8.

8. Huang SM, Harari PM. Modulation of radiation response after epidermal grow factor receptor blocks in squamous cell carcinomas: inhibition of damage repair, cell cicle kinetics a tumours angiogenesis. Clin Cancer res 2000; 6:216674 .

9. Smith BD, Smith GL, Carter D et al. Prognostic significance of vascular endothelial growth factor protein levels in oral and orofaringeal squamous cell carcinoma J Clin Oncol 2000; 2046-52.

10. Padelano Laura Cerizo. Radiation therapy optimization: new strategies for cancer tretament. Rev Oncol 2002; 4(1):49-5212.

11. Mathon NF and Lloyd A. Cell senescence and cancer. Nature Rewiews 2001; 1:203-13.

12. Brown JM, Therapeutic targets in radiotherapy. Int J Radio Oncol Biol Phys 2001; 49(3):9-26.

13. Jordi Giralt and M Aranzuru Eraso. New targets for tumor radiosensitization. Rev Oncol 2002; 4(6):339-43.

14. Kolenbrander Paul E and Palmer Robert J. Human oral bacterial Biofilm in (Microbial Biofilms, edited by Ghannoum and G.A.O' Toole, ASM Press, Washington,2004) 2004; p. 85.

15. Auschill TM, Arweiler MB, Netushild M, Brecs M, Reich E, Sculean A. Spatial distribution in dental biofims. Arch Oral Biol 2001; 46:471-6.

16. Kolenbrander PE, Andersen RN, Blehert DS, England PG, Foster JS and Palmer RJ. Communication among oral bacterial. Microbiol Mol Biol rev 2002; 66:486-5058.

17. Costerton JWW and Steward Philip.-Películas Bacterianas. Investigación y Ciencia, septiembre 2001; 55-7.
18. Bazerque Pablo. Antisépticos y Desinfectantes: Biguanidas y Alexidina. En (Farmacología Odontológica. Mundi, Buenos Aires) p. 567-8.

19. Fried TR, Bradley EH, Allore H. Understanding the treatment preferences of seriously ill patients. N Engl J Med 2002;346:1061-6.

20. Silvestre-Donat, Plaza Costa A, Serrano Martínez MC. Prevención y Tratamiento de las complicaciones derivadas de la radioterapia en pacientes con tumores de cabeza y cuello. Medicina Oral. 1998;3:136-47.

21. Pérez Romasanta LA, Los cuidados de soporte en Oncología Radioterápica.Clin Transl Oncol 2005;7(7):302-5.

22. Manoazul A, Rebelo H. Complicaciones de la radioterapia cérvicofacial. Prevención, diagnóstico y tratamiento multidisciplinario. Avances en Odontoestomatología 1991 (7): 386-96.

23. Loprinzi LCH, Gastineau DA, Foote RL. Complicaciones bucales. En: Abeloff MD, Armitage JO, Niederhuber JE, Kastan MB, Mckenna WG. Pncología Clínica: Ciencia de la oncología Clínica problemas Oncológicos Frecuentes. $3^{a}$ ed. El Servier Churchill Livingstone, 2005 España. p. 3130.

24. Schweiger JW.Oral complications folowing radiation therapy: A five years retrospective report. J Prosthet Dent 1987(58):78-82.

25. Sol Silverman Jr. Complication of Treatment. In (Sol Silverman Jr. Oral Cancer, fourth ed. HalmiltonLondon 1998) p. 91-102.

26. Scully C. Salivary Glands and Saliva: Drug effects on salivary glands:dry mouth. Oral Diseases 2003; 9:165-76.

27. NEWS- Saliva-based oral cancer detection kit available for first time- British Dental Journal 2006; 200-246. 11-Jordi Giralt and M Aranzuru Eraso. New targets for tumor radiosensitization. Rev Oncol 2002;4(6):339-43. 
28. Pretty IA, Gallagher MV, Martin MV, Edgar WM, Higham SM Un estudio para valorar in vitro e in vivo los efectos de una nueva formulación de dentífrico sin detergente y con aceite de oliva. Jorunal of dentistry, 2003;31:327-32.

29. Söderling E, Le Bell A, Kirstilä V, Tenuovo J. Betaine-containing toohpaste relieves subjective symptoms of dry mouth. Acta odontol Scand. 1998; Apr; 56(2): 65-9.

30. Nicander I, Rantanen I, Rozell BL, Söderling E, Ollmar S.The ability of betaine to reduce the irritating effects of detergents assessed visually, histologically and by bioengineering methods. Skin Res Technol.2003 Feb;9(1):50-8.

31. Ship JA, Mccutcheon JA, Spivakovsky S, Kerr AR. Safety and effectiveness of topical dry mouth products containing olive oil, betaina and xylitol in reducing xerostomía for polypharmacy-induced dry mouth. Journal of oral Rehabilitation 2007; 34: 724-32.

32. Veela-Ramirez A, Silverman S, Mayer P et al. Candidal colonization and oral candidiasis in patients undergoing oral and pharingeal radiotherapy. Oral Surg Oral med Oral Pathol Oral radiol 1997; 84: 149-53.

33. Beumer III J, Zlotolow IM, Sharma AB. Restoration of Palate, Tongue-Mandible and Facial efects. In (Sol Silverman Jr. Oral Cancer, fourth ed. Halmiton-London 1998) p. 103-125.30Murray CG, Herson J, Daly TE, et al: Radiation necrosis of the manible: a ten year study Part I; Factors influencing the onset of necrosis. Int $\mathrm{J}$ Radiat Oncol Biol Phys 1980;6:543-8. 